\title{
Clinical and Electrophysiologic Studies on the Wolff-Parkinson-White Syndrome in Aged Cases
}

\author{
Keiji Ueda, M.D., Koei Kitano, M.D., Junichiro Mifune, M.D., \\ Shinichiro Ohkawa, M.D., Masaya Sugrura, M.D., \\ Chizuko Kamata, M.D., Hiroshi Matsuo,* M.D., \\ and Takao Okıмoтo,** M.D.
}

\begin{abstract}
SUMMARY
Clinical and electrophysiologic studies were performed in 10 aged cases (50-82 years of age) with WPW syndrome and following results were obtained: 1) Episodes of paroxysm of supraventricular tachyarrhythmias were observed in 7 and complication of sinus node dysfunction was noted in 3.2 2) P-delta intervals on electrocardiogram exceeding $0.12 \mathrm{sec}$ were observed in 4 cases. 3) Patterns of normalization of QRS complex in 4 cases were characterized by tachycardia-dependent in 2 and bradycardia-dependent in 2. 4) Effective refractory period of the accessory pathway (AP) in antegrade direction exceeded that of $\mathrm{A}-\mathrm{V}$ node in 5 cases and the former exceeding $500 \mathrm{msec}$ was observed in 2 cases. The relations between the changes of the electrophysiologic properties of the AP and altered clinical manifestations of the WPW syndrome in aged cases were discussed.
\end{abstract}

\section{Additional Indexing Words:}

Accessory pathway Sinus node dysfunction Effective refractory period Alternating normalization of QRS complex Phase 4 block

D ECENT advances in electrophysiologic studies utilizing pacing technique 1 have contributed to our understanding of the Wolff-Parkinson-White (WPW) syndrome and related arrhythmias.1-4) However, only a few electrophysiologic studies on WPW syndrome in aged subjects have been reported.2),5)

In this study, the alteration of clinical manifestations of WPW syndrome in 10 aged cases was studied and these modifications were related to the

From the Division of Cardiology, Tokyo Metropolitan Geriatric Hospital and Second Department of Internal Medicine* and Department of Medicine \& Physical Therapy,** Faculty of Medicine, University of Tokyo, Tokyo, Japan.

Address for reprints: Keiji Ueda, M.D., Division of Cardiology, Tokyo Metropolitan Geriatric Hospital, Sakaecho 35-2, Itabashi-ku, Tokyo 173, Japan.

Received for publication May 26, 1977. 
changes of electrophysiologic properties of the accessory pathway (AP) and the atrioventricular (AV) node. Furthermore, sinus node function was assessed in these patients, since it is conceivable that "overdrive suppression "6) of the sinus node by paroxysm of supraventricular tachyarrhythmias (SVT) may be augmented in aged patients. ${ }^{7)}$

\section{Methods}

Study group:

Ten aged patients with recent electrocardiographic documentation of WPW syndrome were studied (Table I). Their ages ranged from 50 to 82 years, with an average of 69.0 years. One case was in 6 th decade, 4 in 7 th, 4 in 8 th, and 1 in 9th decade. Three cases were male and 7 were female.

The diagnostic criteria for WPW syndrome ${ }^{1 / 81}$ used in this study were as follows: 1) P-R interval of $0.12 \mathrm{sec}$ or less (in the presence of normal $P$ waves), 2) QRS duration of $0.11 \mathrm{sec}$ or more, and 3) a distinct delta wave slurring in the initial part of QRS complex. In cases with P-R interval exceeding $0.12 \mathrm{sec}$, the diagnosis of WPW syndrome was confirmed when an electrocardiogram (ECG) obtained successively or on another occasion showed a definitely longer P-R interval, narrower QRS and absence of delta wave.

Methods:

In 10 patients clinical manifestations including documented history of paroxysm of SVT, ECG findings and symptoms associated with SVT were studied. ECG during and after spontaneous cessation of SVT were recorded on magnetic tape to determine the presence or absence of sinus node dysfunction.

Electrophysiologic studies utilizing technique of intracardiac recordings and programmed single atrial premature stimulation (PAS) and rapid atrial pacing were performed in 8 of them (Cases 1 to 8, Tables I and II). His bundle electrogram and right atrial electrogram were simultaneously recorded with surface ECG (Leads I, aV,$V_{1}$ ) by an oscillographic recorder (Electronics for Medicine, DR12) and a magnetic tape recorder. Effective refractory period (ERP) of the AV node and AP in antegrade direction was determined by programmed single atrial premature stimulation (PAS) method during basic sinus rhythm. Sinus node function was also assessed by measuring " sinus node recovery time " ${ }_{61,7)}$ following abrupt cessation of rapid artial pacing or duration of sinus pause after spontaneous cessation of paroxysm of SVT during pacing study. Details of the method of electrophysiologic study have been described elsewhere. ${ }^{7,9)}$

\section{Results}

I. Clinical and electrocardiographic findings (Table I)

1. Incidence of paroxysm of SVT and associated symptoms

Recent episodes of SVT were documented in 7 patients and SVT has recurred in 6, while in 1 patient (Case \#7) the episode of SVT did not recur after recent development of sinus brady-arrhythmia associated with occasional 
Table I. Clinical and

\begin{tabular}{|c|c|c|c|c|c|}
\hline $\begin{array}{l}\text { Case } \\
\text { No. }\end{array}$ & $\begin{array}{c}\text { Name } \\
(\mathrm{HBE} \text { No.) }\end{array}$ & Age & Sex & $\begin{array}{l}\text { Types of } \\
\text { WPW }\end{array}$ & $\begin{array}{l}\text { Mode of Normalization } \\
\text { of QRS Complexes }\end{array}$ \\
\hline 1 & H. W. (\#204) & 50 & M & A & intermittent normalization \\
\hline 2 & H. O. (\#201) & 65 & $\mathrm{~F}$ & A & $\begin{array}{l}\text { alternating normalization } \\
\text { (bradycardia-dependent) }\end{array}$ \\
\hline 3 & H. S. (\#202) & 67 & M & $\mathrm{A}$ & persistent WPW pattern \\
\hline 4 & T. K. (\#224) & 70 & $\mathrm{~F}$ & A & $\begin{array}{l}\text { alternating normalization } \\
\text { (tachycardia-dependent) }\end{array}$ \\
\hline 5 & K. Hi. (\#51) & 71 & $\mathrm{~F}$ & A & $\begin{array}{l}\text { bradycardia-dependent } \\
\text { normalization }\end{array}$ \\
\hline 6 & K. Ho. $(\# 60)$ & 74 & $\mathrm{~F}$ & A & persistent WPW pattern \\
\hline 7 & T.F. $\quad(\# 111)$ & 76 & $\mathrm{~F}$ & B & $\begin{array}{l}\text { tachycardia-dependent } \\
\text { normalization }\end{array}$ \\
\hline 8 & M. K. (\#183) & 82 & $\mathrm{~F}$ & B & intermittent normalization \\
\hline 9 & S. M. & 66 & $\mathbf{F}$ & B & intermittent normalization \\
\hline 10 & S. Y. & 69 & $\mathbf{M}$ & B & intermittent normalization \\
\hline & $\begin{array}{l}\text { Range } \\
\text { Mean }\end{array}$ & \multicolumn{2}{|c|}{$\begin{array}{l}50-82 \\
69.0\end{array}$} & & \\
\hline
\end{tabular}

Abbreviations: $\mathbf{M}=$ male, $\mathbf{F}=$ female, SVT=supraventricular tachyarrhythmia, $\mathrm{P}-\mathrm{R}$ int. $=\mathrm{P}-\mathrm{R}$ interval observed during normalization of $\mathrm{QRS}$ complexes, $\mathrm{PAT}=$ paroxysmal atrial tachycardia,

sinus arrest and junctional escape beats. Fainting occurred at the time of spontaneous cessation of SVT in 1 patient (Case \#8) and prolongation of sinus pause was recorded immediately following abrupt cessation of SVT in 2 (Cases \#1 and \#8).

2. Types of WPW syndrome

According to the classification of Rosenbaum, ${ }^{10)} 6$ cases were of type A and 4 cases of type $B$.

3. Patterns of normalization of QRS complexes ${ }^{11)}$ (Figs. 1-4)

WPW pattern was persistent in only 2 cases (Cases \#3 and \#6) and it was intermittent finding in 4 cases (Cases \#1, \#8, \#9, and \#10), while normalization of QRS complexes was observed in every other beat (alternating normalization of QRS complexes) in 2 cases (Cases \#2 and \#3, Figs. 1 and 2), and bradycardia-dependent normalization (Case \#5, Fig. 3), or tachycardia-dependent normalization of QRS complex (Case \#7, Fig. 4) was noted in other 2 cases.

4. P-delta intervals or P-R intervals on ECG (Fig. 5)

P-delta intervals associated with WPW pattern in 10 cases ranged from $0.08 \mathrm{sec}$ to $0.16 \mathrm{sec}$, an average being $0.116 \pm 0.025$ (SD) sec. P-delta inter- 
Electrocardiographic Findings

\begin{tabular}{|c|c|c|c|}
\hline \multicolumn{4}{|c|}{ Electrocardiographic Findings } \\
\hline Types of SVT & $\begin{array}{l}\text { Sinus Node } \\
\text { Dysfunction }\end{array}$ & P-delta (sec) & $\mathbf{P}-\mathbf{R}$ int. (sec) \\
\hline PAT & $\begin{array}{l}\text { Sinus arrest } \\
\text { following SVT }\end{array}$ & 0.11 & 0.16 \\
\hline None & None & 0.16 & 0.22 \\
\hline PAT & None & $\begin{array}{l}(* 0.12) \\
* * 0.14\end{array}$ & \\
\hline Af & None & 0.11 & 0.14 \\
\hline PAT & None & 0.11 & 0.23 \\
\hline PAT & None & 0.11 & \\
\hline $\begin{array}{l}\text { H/O PAT, Af- } \\
\text { SVT ceased }\end{array}$ & $\begin{array}{l}\text { Sinus arrest, } \\
\text { junctional rhythm }\end{array}$ & 0.13 & 0.20 \\
\hline PAT & $\begin{array}{l}\text { Sinus arrest, } \\
\text { syncope }\end{array}$ & 0.08 & 0.16 \\
\hline None & None & 0.08 & 0.14 \\
\hline None & None & 0.14 & 0.17 \\
\hline & mean $\pm S D$ & $\begin{array}{c}0.08-0.16 \\
0.116 \pm 0.025\end{array}$ & $\begin{array}{c}0.14-0.23 \\
0.178 \pm 0.033\end{array}$ \\
\hline
\end{tabular}

Af $=$ atrial fibrillation

* ECG on June 9, 1973. ** ECG on March 3, 1976

vals exceeded $0.12 \mathrm{sec}$ in 4 cases, they were $0.13 \mathrm{sec}$ in $1,0.14 \mathrm{sec}$ in 2 , and $0.16 \mathrm{sec}$ in 1 case.

P-R intervals associated with normal QRS complex in 8 cases ranged from $0.14 \mathrm{sec}$ to $0.23 \mathrm{sec}$, with an average of $0.178 \pm 0.033$ (SD) sec, in $2 \mathrm{pa}-$ tients it exceeded 0.21 sec.

II. Electrophysiologic study

1. His bundle electrograms (HBE) and PAS study

Results of electrophysiologic studies in 8 cases are shown in Table II.

In 2 cases (Cases \#1 and \#5), since QRS complex remained normal at the time of the study, the conduction over AP was not observed. In Case \#1, ERP of AP could not be determined because of frequent provocation of SVT accompanying narrow QRS complexes by PAS with relatively short coupling intervals.

In other 2 cases with WPW pattern (Cases \#3 and \#6), antegrade conduction over AP occurred up to the ERP of the right atrium and QRS complexes could not be normalized either spontaneously or by PAS at the time of the study.

In the remaining 4 cases (Cases \#2, \#4, \#7, and \#8), normalization of 
(a)

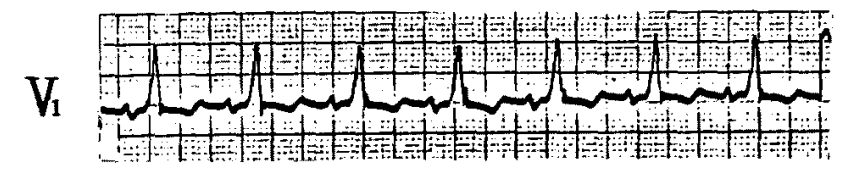

(b)

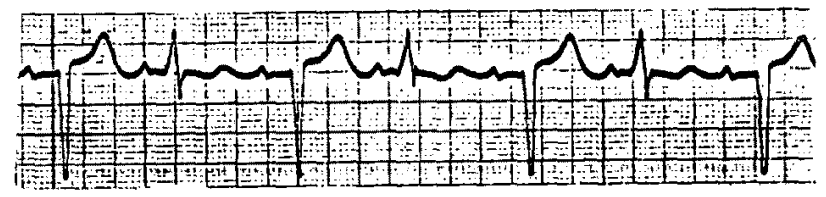

(c)

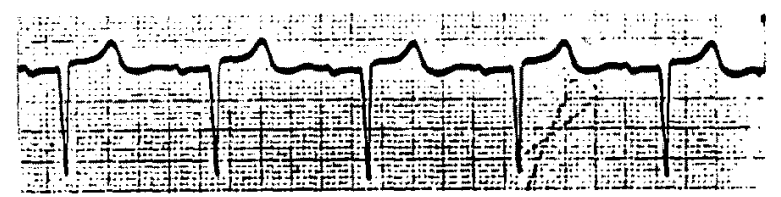

Fig. 1. Ghanges of QRS complexes in lead $V_{1}$ in Gase $\# 2$.

(a) All QRS complexes showed fusion beats, when P-P intervals were 0.66 $\sec$ (Feb. 16, 1976).

(b) Normalization of QRS complexes was observed in every other beat, when P-P intervals were $0.76 \mathrm{sec}$ (Jan. 30, 1976).

(c) All QRS complexes were normalized with $P$-P intervals which ranged from 0.98 to $1.0 \mathrm{sec}$ (Feb. 21, 1976).

(a)

II

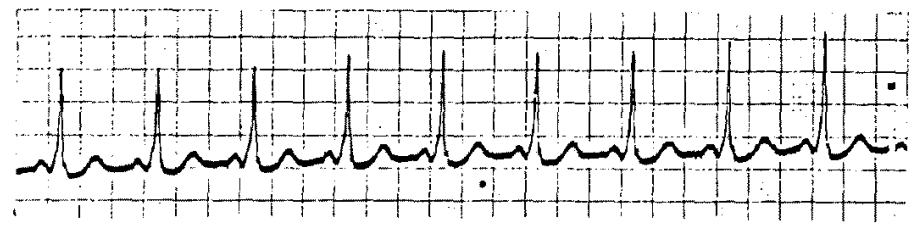

$P-P \quad 0.52 \mathrm{sec}$

(b)

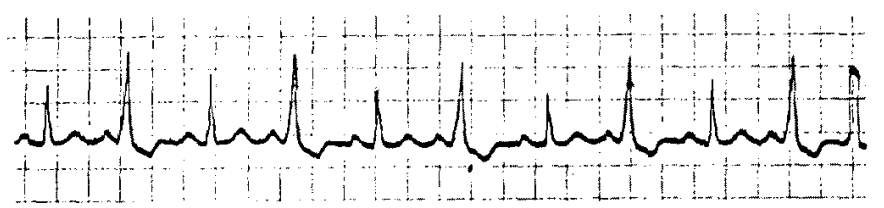

Fig. 2. Changes of QRS complexes in lead II in Case \#4.

(a) All QRS complexes showed WPW pattern, when P-P intervals were $0.60 \mathrm{sec}$.

(b) Normalization of QRS complexes was observed in every other beat, when $\mathrm{P}-\mathrm{P}$ intervals were shortened to $0.52 \mathrm{sec}$. 
July 16, 1974

(a)

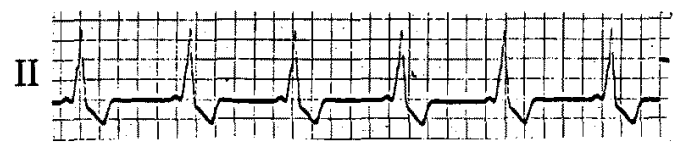

Oct. 22, 1974

(b)

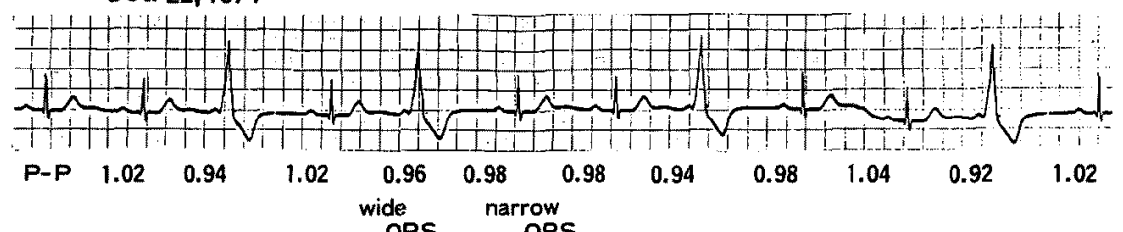

(c)

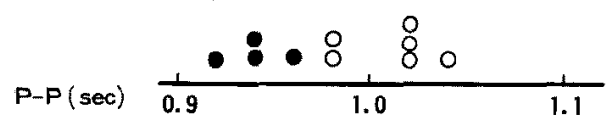

Fig. 3. Relation between preceding P-P interval and shape of QRS complex in Case \#7 (lead II), showing bradycardia-dependent normalization of QRS complex.

(a) All QRS complexes were WPW pattern.

(b) P-P interval which was equal to or exceeding $0.98 \mathrm{sec}$ was followed by normalized QRS complex.

(c) Distribution of P-P intervals and shapes of QRS complexes of ECG shown in (b).

(a)

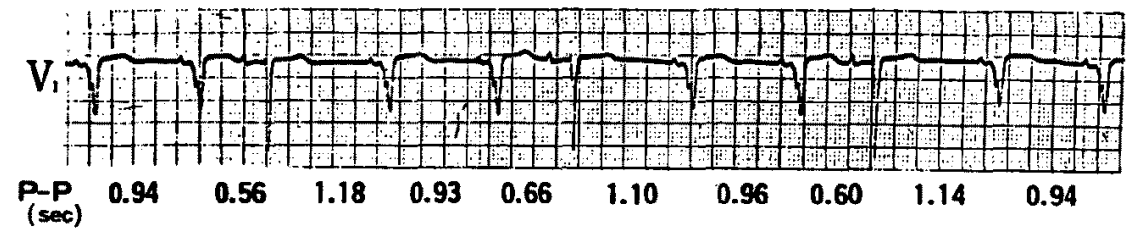

narrow QRS wide QRS

(b)

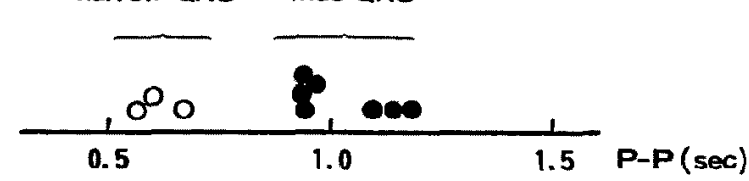

Fig. 4. Relation between preceding $P-P$ interval and shape of QRS complex in Case \#5 (lead II), showing tachycardia-dependent normalization of QRS complex.

(a) Frequent premature atrial contractions with shorter P-P intervals were followed by narrow $Q R S$ complexes.

(b) Distribution of P.P intervals and shapes of QRS complexes of ECG shown in (a). 
QRS complex could be obtained with PAS technique. In these 4 cases, in whom ERP of both AP and A-V node in antegrade direction could be determined, ERP of AP exceeded that of the A-V node.

ERP of AP determined in 6 cases ranged from less than $160 \mathrm{msec}$ (Case

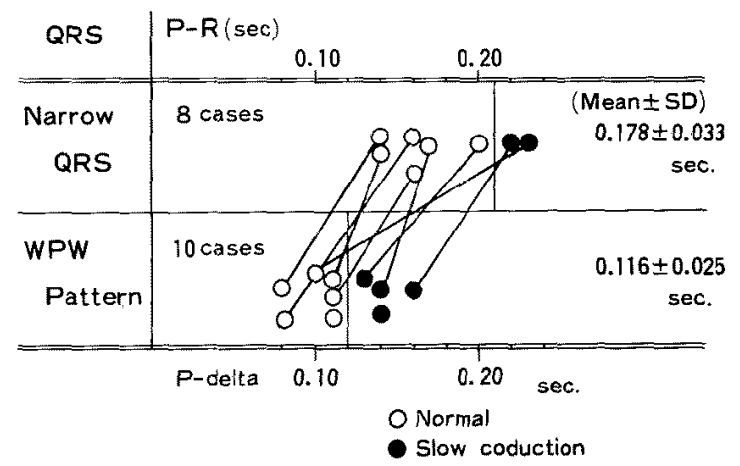

Fig. 5. Distribution of P-R intervals in 8 cases (upper panel) and P-delta intervals in 10 cases (lower panel). Corresponding values in each case are connected by solid lines.

Table II. Results of

\begin{tabular}{|c|c|c|c|c|c|}
\hline \multirow{2}{*}{$\begin{array}{c}\text { Case } \\
\text { No. }\end{array}$} & \multicolumn{5}{|c|}{ Intervals on $\mathrm{HBE}$ (msec) } \\
\hline & $\mathrm{P}-\mathrm{P}$ & $\mathrm{P}-\mathrm{A}$ & $\mathrm{A}-\mathrm{H}$ & $\mathrm{P}$-delta $(\mathrm{P}-\mathrm{R})$ & $\mathrm{H}$-delta $(\mathrm{H}-\mathrm{V})$ \\
\hline \multirow[t]{2}{*}{1} & \multicolumn{5}{|c|}{ Normalized QRS only } \\
\hline & $(650)$ & $(20)$ & $(70)$ & $(130)$ & $(40)$ \\
\hline 2 & 960 & 40 & 140 & 160 & $\begin{array}{r}-20 \\
(40)\end{array}$ \\
\hline \multirow[t]{2}{*}{3} & \multicolumn{5}{|c|}{ WPW pattern only } \\
\hline & 710 & 40 & 90 & 140 & 10 \\
\hline 4 & 580 & 30 & 55 & 85 & 0 \\
\hline \multirow[t]{2}{*}{5} & \multicolumn{5}{|c|}{ Normalized QRS only } \\
\hline & (985) & $(30)$ & $(130)$ & $(205)$ & $(45)$ \\
\hline \multirow[t]{2}{*}{6} & \multicolumn{5}{|c|}{ WPW pattern only } \\
\hline & 660 & 90 & 130 & 110 & -10 \\
\hline 7 & 1,306 & 33 & 114 & 130 & -16 \\
\hline 8 & 1,150 & 30 & $*$ & 80 & * \\
\hline $\begin{array}{l}\text { Range } \\
\text { Mean }\end{array}$ & & & & & \\
\hline
\end{tabular}

Numbers in parenthesis indicate intervals observed during normalization of QRS complex.

Abbreviations : $\mathrm{RA}=$ right atrium, $\mathrm{AVN}=$ atrioventricular node, $\mathrm{AP}=$ accessory pathway, SVT = supraventricular tachyarrhythmias, $\mathrm{PAS}=$ premature atrial stimulation, $\mathrm{PAT}=$ paroxysmal atrial 
\#6) to $810 \mathrm{msec}$, an average being $413 \mathrm{msec}$. ERP of AP exceeding $300 \mathrm{msec}$ was noted in 4, of whom it exceeded $500 \mathrm{msec}$ in 2 cases (Cases \#2 and \#7).

In 5 cases, antegrade conduction over the $\mathrm{A}-\mathrm{V}$ node occurred up to the ERP of the right atrium, which ranged from 160 to $390 \mathrm{msec}$. In the other 2 cases (Cases \#1 and \#7), ERP of A-V node in antegrade direction were $360 \mathrm{msec}$ and $540 \mathrm{msec}$, respectively. P-delta interval exceeding $120 \mathrm{msec}$ during basic sinus rhythm was recorded in 3 cases, in one of them A-H interval was also prolonged, while it was normal in the other 2 cases.

From ECG and electrophysiologic studies, the presence of "bundle of Kent" was suggested in 6 cases in whom recording of HBE and PAS study were performed during WPW pattern.

2. SVT and sinus node function (Table II)

Paroxysm of SVT was initiated by properly timed single atrial stimulation in 4 cases.

Sinus node recovery time after rapid atrial pacing or sinus pause following spontaneous cessation of SVT observed during the study was prolonged in 2, while it was normal in 5 other cases. In 1 patient sinus node recovery

Electrophysiologic Studies

\begin{tabular}{|c|c|c|c|c|c|}
\hline \multicolumn{3}{|c|}{$\begin{array}{l}\text { Atrioventricular Effective } \\
\text { Refractory Period (msec) }\end{array}$} & \multirow{2}{*}{\multicolumn{2}{|c|}{$\begin{array}{l}\text { SVT } \\
\text { Initiated by } \\
\text { PAS }\end{array}$}} & \multirow[t]{2}{*}{ Sinus Node Recovery Time } \\
\hline RA & AVN & AP & & & \\
\hline Undetermined & 360 & Undetermined & $(+)$ & PAT & $\begin{array}{l}\text { Sinus arrest } \\
\text { with junctional escape }\end{array}$ \\
\hline 390 & $<390$ & 510 & & & Normal \\
\hline 260 & Undetermined & $<260$ & $(+)$ & $\mathrm{AF}$ & Normal \\
\hline 200 & $<200$ & 330 & $(+)$ & PAT & Normal \\
\hline 320 & $<320$ & Undetermined & & & Normal \\
\hline 160 & $<160$ & $<160$ & & & Normal \\
\hline 440 & 540 & 810 & & & $\begin{array}{l}\text { Undetermined due to } \\
\text { premature ectopic } \mathrm{P} \text { wave }\end{array}$ \\
\hline 300 & $<300$ & 390 & $(+)$ & PAT & Sinus arrest for $2.5 \mathrm{sec}$ \\
\hline $160-440$ & $<160-450$ & $<160-810$ & & & \\
\hline 295 & 324 & 413 & & & \\
\hline
\end{tabular}




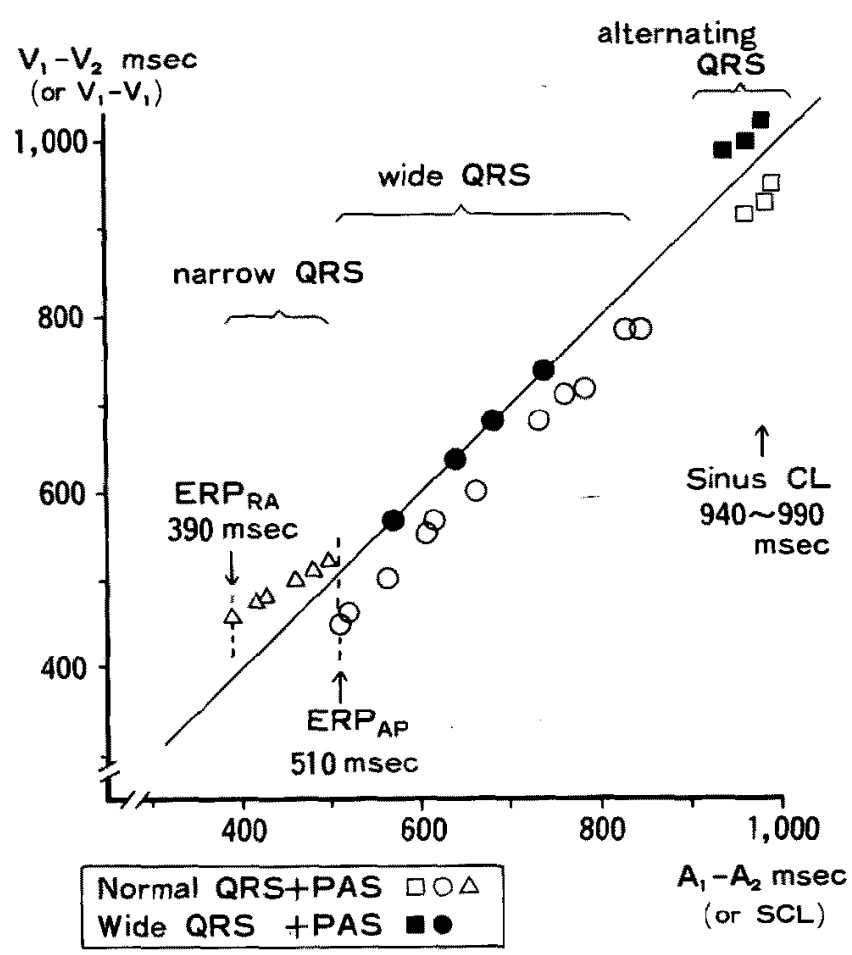

Fig. 6. Changes of QRS complexes during basic sinus rhythm and following premature atrial stimulation (PAS) in Case \#2.

During sinus rhythm, P-P interval of sinus cycles (SCL) is plotted on abscissa and R-R interval $\left(V_{1}-V_{1}\right)$ on ordinate and during PAS study coupling interval of PAS $\left(A_{1}-A_{2}\right)$ on abscissa, R-R interval $\left(V_{1}-V_{2}\right)$ on ordinate.

timc could not be estimated because of occurrence of ectopic premature atrial contraction immediately after the cessation of rapid pacing.

III. Presentation of cases showing unusual electrophysiologic properties of AP

In Case \#2 (Fig. 6), AP became refractory in other beat during slow rate with P-P interval exceeding $900 \mathrm{msec}$, while PAS with shorter coupling interval was propagated over AP up to the refractoriness of AP ( $510 \mathrm{msec}$ ). Fig. 7 illustrates a possible mechanism of alternation of narrow and wide $Q R S$ complexes, while P-P interval remains exactly constant. The first beat shown in the ladder diagram in Fig. 7 is a fusion beat. In the second beat, A-V transmission of the atrial impulse is feasible only through the A-V nodal pathway, thus giving rise to a narrow $Q R S$ complex. The conduction over Kent bundle in this beat is assumed to be blocked because of spontaneous slow diastolic depolarization (phase 4 block). If Kent bundle is depolarized in the retrograde direction from the ventricle, renewal of the action potential 

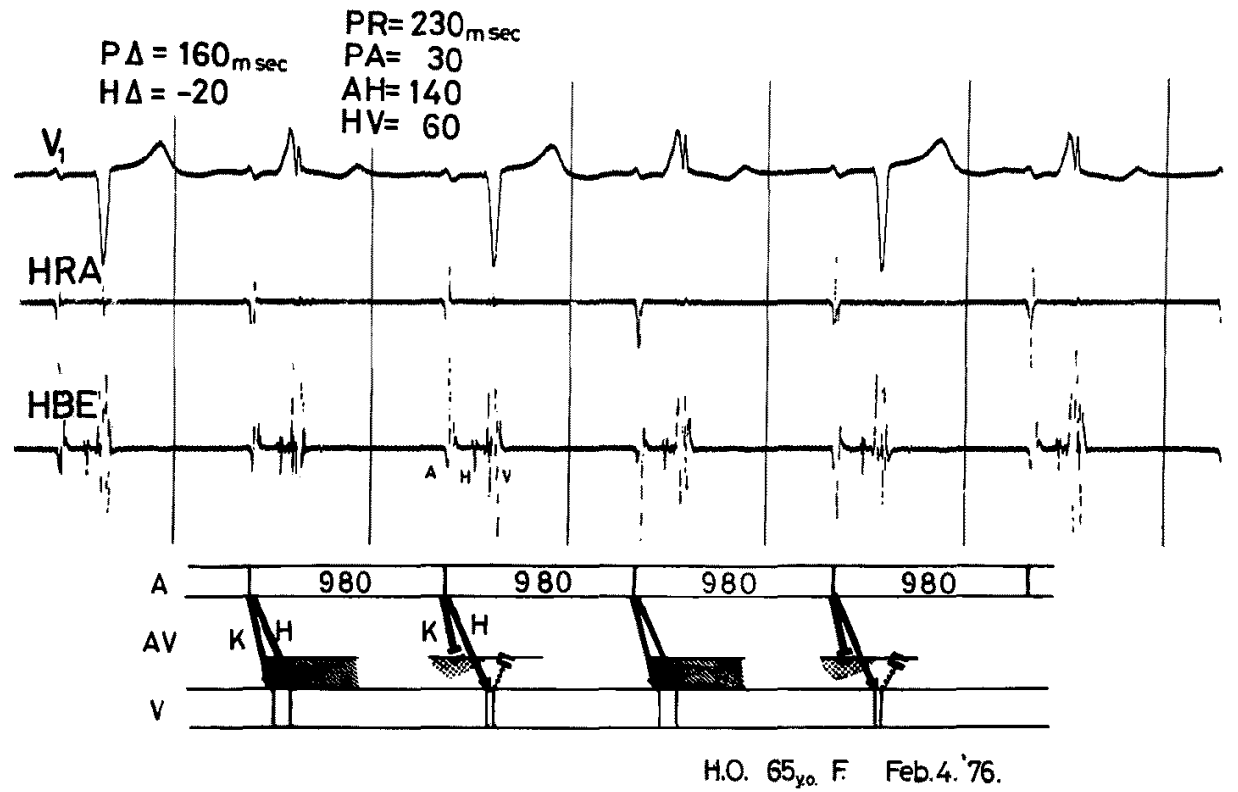

Fig. 7. Intracardiac electrograms in Case \#2 showing alternating normalization of QRS complex (see text). K: Kent bundle, H: A-V node-His bundle, HRA: high RA electrogram

\section{Atrial Pacing $(150 / \mathrm{min})$}

HRA
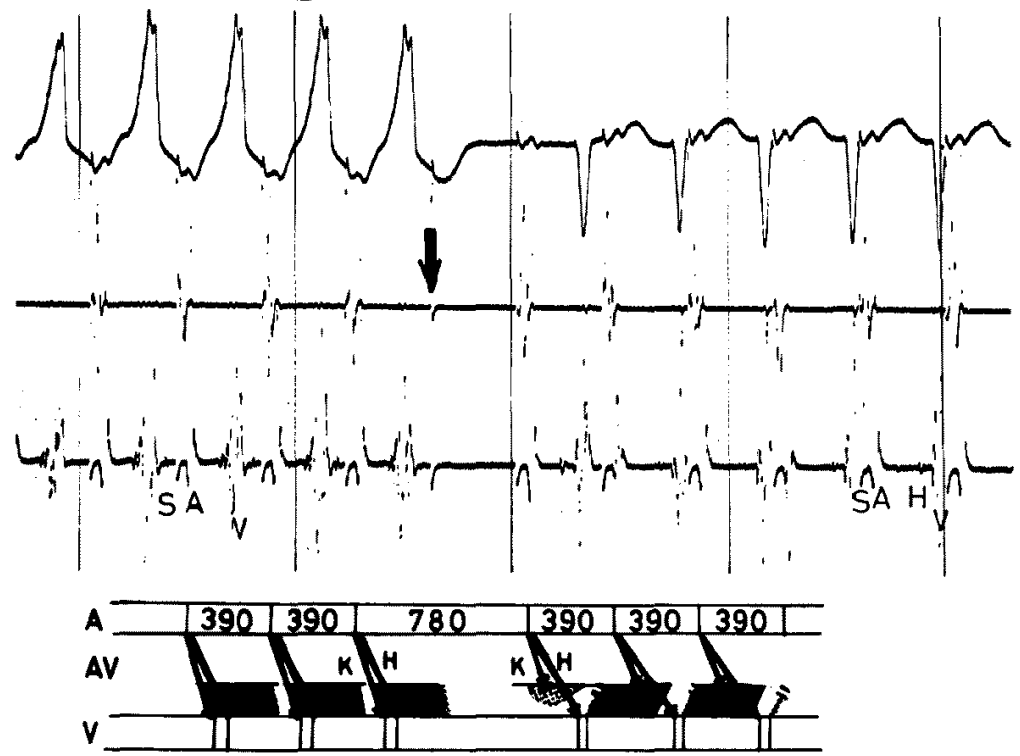

\section{H.O. 65 xo. F. Feb4.'76.}

Fig. 8. Intracardiac electrograms in Case \#2 during rapid atrial pacing (see text).

Arrow in the middle of the record indicates the stimulus which failed to capture the atrium. Abbreviations as in Fig. 7. 
and resetting of cycle of Kent bundle can occur, thus permitting subsequent antegrade conduction, resulting again in a fusion beat in the third beat.

A record obtained in Case \#2 during rapid atrial pacing at a rate of 150 beats/min is shown in Fig. 8, which illustrates $1: 1 \mathrm{~A}-\mathrm{V}$ conduction except a pacing stimulus in the middle of the record, indicated by an arrow, which failed to capture the atrium. It should be noted that QRS complex showed abrupt normalization after the non-captured stimulus. This phenomenon can be explained by the same assumption mentioned above. In the diagram shown in the bottom of Fig. 8, the initial 3 successive beats are fusion beats with predominant conduction over $\mathrm{AP}$, while the $\mathrm{P}$ wave immediately after the pacing stimulus that failed to activate the atrium is followed by narrow QRS, indicating the failure of conduction through AP. It can be assumed

(a)
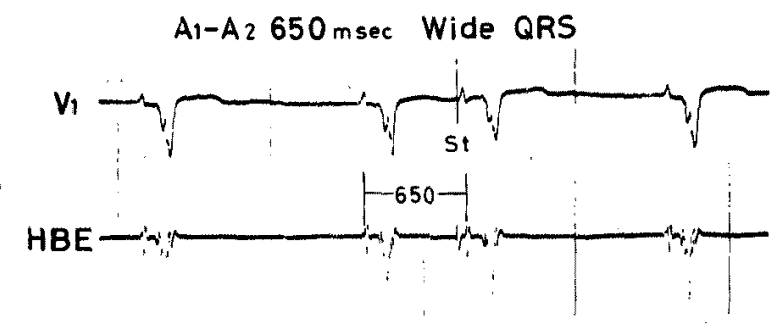

(b)

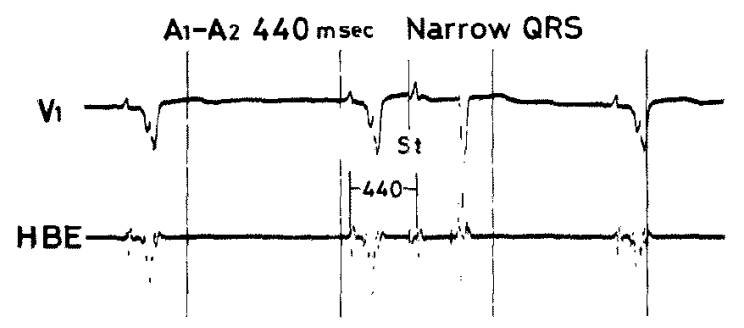

(c)

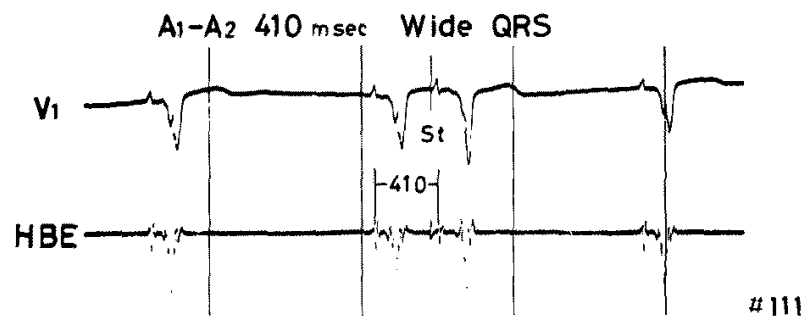

Fig. 9. Relation between coupling intervals of PAS and shapes of QRS complexes in Case \#7.

(a) PAS with coupling interval of $650 \mathrm{msec}$ was followed by wide QRS complex.

(b) When coupling interval was shortened to $440 \mathrm{msec}$, subsequent $\mathrm{QRS}$ complex was narrow.

(c) When coupling interval was further shortened to $410 \mathrm{msec}$, subsequent QRS complex became wide. 
that this failure of conduction is due to mechanism of phase 4 block. Subsequent block of atrial impulses through AP may be explained by phase 3 block due to prolonged REP (510 msec).

Unusual electrophysiologic properties of AP was also observed in another case. In Case \#7, with the i.v. injection of $1.0 \mathrm{mg}$ of atropine basic P$P$ interval changed from $1,306 \mathrm{msec}$ to $1,093 \mathrm{msec}$ and ERP of A-V node, $\mathrm{AP}$, and right atrium changed from 540 to $440 \mathrm{msec}$, from 810 to $630 \mathrm{msec}$, and from 440 to $360 \mathrm{msec}$, respectively. PAS study after atropine injection (Fig. 9) revealed that PAS with coupling interval between 630 and $420 \mathrm{msec}$ was followed by narrow QRS complex, while PAS with coupling interval between 410 and $380 \mathrm{msec}$ again showed wide QRS complex, indicating unexpected conduction of Kent bundle (supernormal conduction of AP).

\section{Discussion}

Studies on the natural history of WPW syndrome ${ }^{8), 12)}$ suggest that electrocardiographic signs of preexcitation disappear with increasing age in a significant number of patients. Clinical observation of diminished incidence of tachycardia with increasing age was attributed to progressive lengthening of refractory period with ultimate block of AP, ${ }^{5)}$ while electrophysiologic study reported by others ${ }^{2}$ did not confirm any significant difference in the length of refractory period between different age groups. In the present study on 10 aged patients, a mean value of the length of ERP was $413 \mathrm{msec}$, which is longer than those previously reported for any age group, ${ }^{2,5)}$ and this finding may support the hypothesis of progressive lengthening of refractory period with increasing age.

The incidence of documented paroxysm of SVT in this study was $70 \%$, which indicates that the recurrence of SVT is still a major clinical problem in aged patients with WPW syndrome. The high incidence of paroxysm of SVT may have additional clinical significance in aged patients, since overdrive suppression of the sinus node by SVT may be exaggerated when aged patient with WPW syndrome develops sinus node dysfunction, and this was recognized in 3 cases in the present study. In addition to various mechanisms which are responsible for initiation of sustained SVT involving AP and/or A-V node in WPW syndrome, a reentry mechanism involving the sinoatrial junction initiated by ectopic premature atrial contraction may be another possibility in of SVT sick sinus syndrome associated with WPW syndrome.

Case of preexcitation with prolonged P-delta interval due to slow Kent bundle conduction has been reported. ${ }^{13)}$ In this study 4 cases showed prolonged P-delta interval exceeding $0.12 \mathrm{sec}$. In 3 cases (Cases \#2, \#7, and 
\#10), diagnosis of WPW syndrome could be verified by the documentation of longer P-R intervals and constant P-J intervals with normalized QRS complexes on other occasions. In remaining 1 case (Case \#3), lengthening of $P$ delta interval from $0.12 \mathrm{sec}$ to $0.14 \mathrm{sec}$ at 2 years' interval was recorded (Table I). In addition, results of electrophysiologic study performed in 3 cases (Cases \#2, \#3, and \#7) were compatible with the presence of Kent bundle as the anatomical basis of widened QRS with initial slurring in these cases. Marked prolongation of ERP of AP in Cases \#2 and \#7, $510 \mathrm{msec}$ and $810 \mathrm{msec}$, respectively, is in accordance with a case showing slow Kent bundle conduction reported by Rosen et al.13)

QRS complexes are often normalized in cases with WPW syndrome. Recording of $\mathrm{HBE}$ during spontaneous or induced normalization of QRS complexes suggested that QRS complexes became normal in the following circumstances $^{11}$; 1) when AP failed to conduct at high atrial rates and also early premature beats; 2) AP became refractory by virtue of phase 4 depolarization after long pauses and in slow rate; 3) when the origin of the ventricular impulses was situated within the His bundle below the take-off of AP; and 4) in circumstances in which conduction velocity through A-V nodeHis axis supercede that of AP. Among 10 aged cases included in the present study, normalization of QRS complex could be related to tachycardia in 2 cases (Cases \#4 and \#7) and to bradycardia in 2 cases (Cases \#2 and \#5). Prolonged ERP over $500 \mathrm{msec}$ in Cases \#2 and \#7, suggesting altered electrophysiologic properties of AP, are in accordance with observation of normalization of QRS complexes on ECG.

In conclusion, it may be stated that although occurrence of changes of clinical and electrocardiographic manifestations in some aged patients with WPW syndrome was shown in this small series, more systemic studies, including preferably electrophysiologic study, are mandatory to elucidate the natural history of WPW syndrome.

\section{Referenaes}

1. Narula OS: Wolff-Parkinson-White syndrome. A review. Circulation 47: 872, 1973

2. Wellens HJJ, Lie KI, Janse MJ: Conduction System of the Heart. HE Stenfert Kroese BV, Leiden, p 157, 1976

3. Durrer D, Schoo L, Schuilenberg RM, Wellens HJJ: The role of premature beats in the initiation and the termination of supraventricular tachycardia in the Wolff-Parkinson-White syndrome. Circulation 36: 644, 1967

4. Wellens HJJ: Contribution of cardiac pacing to our understanding of the Wolff-ParkinsonWhite syndrome. Brit Heart.] 37: 231, 1975

5. Mandel WI, Laks MM, Fink B, Obayashi K: Comparative electrophysiologic features of the WPW syndrome in the pediatric and adult patient. Am J Cardiol 33: 155, 1974 (abstract) 
6. Mandel WJ, Hayakawa H, Allen HN, Danzig R, Kermaier AI: Assessment of sinus node function in patients with the sick sinus syndrome. Circulation $46: 761,1972$

7. Okimoto T, Ueda K, Kamata C, Yoshida H, Ohkawa S, Hiraoka K, Kuwajima I Sugiura M, Murakami M, Matsuo $H$ : Sinus node recovery time and abnormal postpacing phase in the aged patierits with sick sinus syndrome. Jap Heart J 17: 290, 1976

8. Berkman NL, Lamb LE: The Wolff-Parkinson-White electrocardiogram. A follow-up study of five to twenty-eight years. New Engl J Med 278: 492, 1968

9. Ueda K, Kamata C, Matsuo H, Ohkawa S, Okimoto T, Sugiura M: A study on sinoatrial conduction in the aged. Jap Heart J 18: 143, 1977

10. Rosenbaum FF, Hecht HH, Wilson FN, Johnston FD: The potential variations of the thorax and the esophagus in anomalous atrioventricular excitation (Wolff-Parkinson-White syndrome). Am Heart J 29:281, 1945

11. Massumi RA, Vera Z: Patterns and mechanisms of QRS normalization in patients with Wolff-Parkinson-White syndrome. Am J Cardiol 28: 541, 1971

12. Flensted-Jensen E: Wolf-Parkinson-White syndrome. A long-term follow-up of 47 cases. Acta Med Scand 186: 65, 1969

13. Rosen KM, Lopez-Arostegui F, Pouget JM: Pre-excitation with normal PR intervals. A case secondary to slow Kerit bundle conduction. Chest 62: 581, 1972 